\title{
Gender and Age Differences in Safety-Oriented Personality Style or Phobicentric Psychopathology (SOPS/PCP)
}

\author{
Patrick Bickersteth ${ }^{1}$, Xinxin, Zhang ${ }^{2}$, Xiaozhou Zhang ${ }^{3}$ \\ ${ }^{1}$ PB Psychological Services, St Albert, Alberta, Canada \\ ${ }^{2}$ Centre for Research in Applied Measurement and Evaluation, University of Alberta, Edmonton, Alberta, Canada \\ ${ }^{3}$ Department of Educational Psychology, University of Alberta, Edmonton, Alberta, Canada \\ Correspondence: Patrick Bickersteth, PB Psychological Services, St Albert, Alberta, Canada.
}

Received: October 22, 2018

Accepted: November 14, 2018

Available online: November 21, 2018

doi:10.11114/ijsss.v6i12.3703

URL: https://doi.org/10.11114/ijsss.v6i12.3703

\begin{abstract}
This study investigates differences in gender and age in the Safety-Oriented Personality Style or Phobicentric Psychopathology (SOPS/PCP). Comparisons are made with Neuroticism in the Big 5 or Five Factor Model to further distinguish it from SOPS/PCP. The results show similarity in age but not gender differences between the two constructs. Also, the location of the participants (Canada or USA) was not significant. The study is an initial step in accumulating basic facts about SOPS/PCP.
\end{abstract}

Keywords: Big 5 Neuroticism, five factor model, plaster, continuous change

\section{Introduction}

The Safety-Oriented Personality or Phobicentric Psychopathology (SOPS/PCP) has been previously discussed (Bickersteth, Zhang \& Guo, 2018). That study was the first time SOPS/PCP was proposed as a personality type. Its authors described the personality as follow:

“. . . the fear-anxiety construct underlying SOPS/PCP is to be broadly construed as a pervasive and persistent, reactive condition that is rooted in fear emotion and may be triggered by actual or perceived threat. Its very serious or severe expression would characterize it as a disorder. In other words, a phobicentric psychopathology is believed to develop under specific conditions from normal or adaptive fear to pathological reactivity. As emotion-based behavioral functioning it is further explained as controlled by neurobiological activity. Since SOPS represents characteristics attributable to a normal emotional reaction of fear, which develops into a worse form of a disordered pattern of persistent fearfulness or anxiety it fits well on a dimensional continuum. "The absence of any other previous study limits the present study's ability to present longitudinal research on SOPS/PCP.

Big 5, or the Five Factor Model, Neuroticism (N) was seen as, in general, most closely associated with SOPS/PCP based on their trait constituents, though not to the extent of suggesting total overlap (Author, 2018). Previous research has revealed that $\mathrm{N}$ has demonstrated a relatively consistent pattern in connection with gender and age. Without any previous research on this new psychopathology however, comparable information on its gender and age characteristics is not available, particularly in view of similarity with $\mathrm{N}$. The present study is aimed at providing the initial (and therefore preliminary) data on these topics. In regard to gender many studies have seemed to present substantial evidence that females tended to be higher than men in N. Accordingly the current study will address the gender pattern in SOPS/PCP. Research on age differences in personality, particularly relating to Big 5 traits, including N, originally indicated little change in the mean age level of personality in adulthood with Costa and McCrae (1988) concluding at one point that "personality is stable after age 30" (p. 853). This "set like plaster" view seemed to have evoked an opposing view, the contextual or "persistent change" position. Srivastava, John, Gosling and Potter (2003) who proposed it seemed to resolve the controversy in favor of a continuously changing pattern in personality. A question arises as to where SOPS/PCP would sit in relation to this dichotomy. Because this sample came from the United States and Canada, countries with very similar socio-cultural patterns, the study additionally considered the similarity of the samples from the two countries with respect to SOPS/PCP. In sum, the present study intends to determine, in relation to $\mathrm{N}$, whether in general a higher level of SOPS/PCP is evident in women; with which of the "plaster" or "change" 
propositions SOPS/PCP would align; and whether there is a difference in the samples from Canada and the United States.

\section{Review of the Literature}

Studies comparing the mean levels of $\mathrm{N}$ in males and females have consistently shown women higher than men (Weisberg, DeYoung, \& Hirsh, 2011; Banzhaf et al., 2012). These results have been reported in different kinds of investigations, such as with cross-national and cross-cultural samples (Kajonius \& Mac Giolla, 2017; Schmitt, Realo, Voracek, \& Allik, 2008; McCrae et al., 2004), older age ranges (Chapman, Duberstein, Sörensen, \& Lyness, 2007) and test instrument validation (Xi et al., 2018).

Research results on age patterns of $\mathrm{N}$ uniformly indicate a reduction in $\mathrm{N}$ with increasing age in a variety of settings and research designs - for example, in longitudinal and/or sectional studies (Roberts \& Mroczek, 2008; Rantanen, Metsäpelto, Feldt, Pulkkinen, \& Kokko, 2007; McCrae et al., 1999), using large samples (Lehmann, Denissen, Allemand \& Penke, 2013; Lucas \& Donnellan, 2009), with various national samples (Wortman, Lucas, \& Donnellan, 2012), using structural models (McCrae et al., 2004) and meta-analytic studies (Roberts, Walton, \& Viechtbauer, 2006).

Based specifically on the Big 5 Inventory (BFI), the relevant research information seems to indicate an expectation of commonality with respect to differences in personality traits between Canadians and Americans. In a key study the authors state: “...Although these results suggest geographical differences in personality profiles, countries were overall within less than half a standard deviation from each other. Again, we reason that this finding suggests similarities rather than differences." (Kajonius \& Mac Giolla, 2017).

\section{Materials and Methods}

\subsection{Measures}

The Safety-Oriented Personality Style or Phobicentric Psychopathology Individual Questionnaire (SOPS/PCPIQ). To assess SOPS/PCP attributes the SOPS/PCPIQ (Bickersteth, et al., 2018) - were administered. SOPS/PCPIQ consists of 29 items that measure the safety-oriented personality style using a six-point Likert-style scale, with a range from 0 (Never) to 5 (Very often). These items describe the SOPS/PCP attributes that were consistently displayed and likely to be recognized and accepted, especially by the individual with SOPS/PCP. The internal and test retest reliability of the SOPSIQ were 0.87 , which suggests a high internal reliability and 0.59 , which indicates a moderate reliability. And the SOPS/PCPIQ is convergently and divergently valid (Bickersteth, et al., 2018)

\subsection{Sample}

406 people volunteered to participate in the study by Bickersteth et al. (2018). They were described as English-speaking adults aged between 18 and 80+ years from the United States and Canada (see Table 1). Among the 406 people, 286 were identified as exhibiting SOPS/PCP because they reported having often or very often experienced at least one of the six traumas included in items 24 to 29 . These 286 people are the focus of the present study. Table 2 presents their demographics.

Table 1. Demographic data $(\mathrm{N}=406)$

\begin{tabular}{ccc}
\hline Gender & Frequency & Percent \\
\hline Female & 217 & 53.5 \\
Male & 188 & 46.3 \\
Other & 1 & 0.2 \\
Total & 406 & 100 \\
\hline Age & Frequency & Percent \\
\hline $18-39$ & 142 & 35.0 \\
$40-59$ & 130 & 32.0 \\
60 and higher & 134 & 33.0 \\
Total & 406 & 100 \\
\hline Current country & Frequency & Percent \\
\hline United States & 202 & 49.8 \\
Canada & 204 & 50.2 \\
Total & 406 & 100.0 \\
\hline
\end{tabular}


Table 2. Demographic data $(\mathrm{N}=286)$

\begin{tabular}{ccc}
\hline Gender & Frequency & Percent \\
\hline Female & 159 & 55.6 \\
Male & 126 & 44.1 \\
Other & 1 & 0.3 \\
Total & 286 & 100 \\
\hline Age & Frequency & Percent \\
\hline $18-39$ & 104 & 36.4 \\
$40-59$ & 99 & 34.6 \\
60 and higher & 83 & 29.0 \\
Total & 286 & 100 \\
\hline Current country & Frequency & Percent \\
\hline United States & 137 & 47.9 \\
Canada & 149 & 52.1 \\
Total & 286 & 100.0
\end{tabular}

3.3 Design and Procedures

Research questions and statistical methods were as follows:

1) Are there gender differences in overall SOPS/PCP? Independent t-test was used to check whether there was a significant difference between females and males on the average SOPS/PCPIQ scores.

2) Are there gender differences in individual SOPS/PCPIQ? Multiple independent t-tests were used to check whether there was a significant difference between females and males on the individual SOPS/PCPIQ scores.

3) Are there age differences in overall SOPS/PCP? One-way ANOVA was used to check whether there was a significant difference between young (18-39), middle (40-59), and older (60 and higher) age groups on the average SOPS/PCPIQ scores.

4) Are there age differences in individual SOPS/PCP? Multiple one-way ANOVAs were used to check whether there was a significant difference between young (18-39), middle (40-59), and older (60 and higher) age groups on the individual SOPS/PCPIQ scores.

5) Are there location differences in overall SOPS/PCP? Independent T-test was used to check whether there was a significant difference between people living in United States and Canada on the average SOPS/PCPIQ scores.

6) Are there location differences in individual SOPS/PCP? Multiple independent t-tests were used to check whether there was a significant difference between people living in United States and Canada on the individual SOPS/PCPIQ scores.

\section{Results}

Statistical analyses were performed using the Statistical Package for the Social Sciences (SPSS), version 24.

\subsection{Gender Differences in Overall SOPS/PCPIQ Scores}

Independent t-test revealed that there was no significant difference between females and males on the average SOPS/PCPIQ score: $\mathrm{t}(232.93)=1.46, \mathrm{p}=0.15>0.05$.

\subsection{Gender Differences in Individual SOPS/PCPIQ Scores}

Table 3 presents the related statistics. Column 1 lists the 29 items of SOPS/PCPIQ, which measure the SOPS/PCP attributes. Columns 2 to 5 provide the corresponding group statistics including group sample size, mean, and standard deviation. The last (column 6) shows the results of independent t-tests. Since multiple t-tests were conducted we set alpha as 0.001 , to avoid inflated type I error. As the table shows, only 1 out of 29 characteristics of SOPS indicated a gender difference - specifically, item 21: I worry often about many things. For this item, females $(\mathrm{M}=3.21, \mathrm{SD}=1.40$, $\mathrm{N}=159)$ scored higher than males $(\mathrm{M}=2.53, \mathrm{SD}=1.48, \mathrm{~N}=126): \mathrm{t}(283)=3.95, \mathrm{p}<.001$, two-tailed. The difference of 0.68 scale points was medium (Cohen's $d=0.47$ ). 
Table 3. Gender differences in individual SOPS/PCPIO scores

\begin{tabular}{|c|c|c|c|c|c|}
\hline Item & Group & $\mathbf{N}$ & Mean & $\begin{array}{c}\text { Std. } \\
\text { deviation }\end{array}$ & $\mathbf{t}(\mathbf{d f})$ \\
\hline \multirow[b]{2}{*}{ 1)It is normal to be unsure that you are safe from being harmed or hurt } & Female & 159 & 2.73 & 1.363 & \multirow[b]{2}{*}{-0.10} \\
\hline & Male & 126 & 2.75 & 1.296 & \\
\hline \multirow[b]{2}{*}{ 2)It is easy for people to hurt others with unfair criticism or blame } & Female & 159 & 3.59 & 1.104 & \multirow[b]{2}{*}{1.28} \\
\hline & Male & 126 & 3.41 & 1.248 & \\
\hline \multirow{4}{*}{$\begin{array}{l}\text { 3)I look for all the compliments and praise I am due } \\
\text { 4)I often say so when it feels like life is unfair or things are not going my way } \\
\text { or in my favor }\end{array}$} & Female & 159 & 2.2 & 1.216 & \multirow[b]{2}{*}{0.02} \\
\hline & Male & 126 & 2.2 & 1.464 & \\
\hline & Female & 159 & 2.47 & 1.301 & \multirow[b]{2}{*}{0.27} \\
\hline & Male & 126 & 2.43 & 1.371 & \\
\hline \multirow[b]{2}{*}{ 5)More than a few times a day I feel frustrated or upset } & Female & 159 & 2.3 & 1.362 & \multirow[b]{4}{*}{1.18} \\
\hline & Male & 126 & 2.14 & 1.343 & \\
\hline \multirow{2}{*}{$\begin{array}{l}\text { 6)It is very uncomfortable whenever others find fault with one's appearance or } \\
\text { image }\end{array}$} & Female & 159 & 3.06 & 1.318 & \\
\hline & Male & 126 & 2.87 & 1.405 & \\
\hline \multirow[b]{2}{*}{ 7)It is difficult to wait for people or things } & Female & 159 & 2.8 & 1.296 & \multirow[b]{2}{*}{0.39} \\
\hline & Male & 126 & 2.74 & 1.316 & \\
\hline \multirow[b]{2}{*}{ 8)I probably speak or act in haste at times } & Female & 159 & 2.65 & 1.136 & \multirow[b]{2}{*}{0.86} \\
\hline & Male & 126 & 2.53 & 1.257 & \\
\hline \multirow[b]{2}{*}{ 9)I often regret things soon after I say or do them } & Female & 159 & 2 & 1.317 & \multirow[b]{2}{*}{-2.14} \\
\hline & Male & 126 & 2.33 & 1.225 & \\
\hline \multirow{2}{*}{$\begin{array}{l}\text { 10)Some of my statements could be (or have been) described as sarcastic } \\
\text { humor }\end{array}$} & Female & 159 & 3.18 & 1.405 & \\
\hline & Male & 126 & 3.21 & 1.237 & -0.20 \\
\hline & Female & 159 & 2.16 & 1.394 & \\
\hline 11)I may sometimes react very strongly or "lose it" & Male & 126 & 2.2 & 1.386 & -0.25 \\
\hline 12)Many situations are difficult in a relationship (whether at work, socially, in & Female & 159 & 2.74 & 1.219 & \\
\hline the family and/or in romantic situations) & Male & 126 & 2.66 & 1.272 & 0.52 \\
\hline 13)The things that make a person very defensive or feel offended are always & Female & 159 & 2.11 & 1.297 & \\
\hline around you & Male & 126 & 2.26 & 1.316 & -0.96 \\
\hline & Female & 159 & 4.04 & 0.881 & \\
\hline 14)It is always very important to get as much information as there is & Male & 126 & 3.95 & 0.902 & 0.86 \\
\hline & Female & 159 & 3.76 & 1.003 & \\
\hline 15)Order, tidiness and cleanliness are very important & Male & 126 & 3.61 & 1.117 & 1.19 \\
\hline 16)I have a definite liking or dislike for certain textures, colors, patterns and/or & Female & 159 & 3.13 & 1.372 & \\
\hline motion & Male & 126 & 2.69 & 1.467 & 2.58 \\
\hline 17)It might seem to others that my behavior is opposite to or inconsistent with & Female & 159 & 2.3 & 1.325 & \\
\hline other behaviors in similar situations & Male & 126 & 2.33 & 1.219 & -0.15 \\
\hline 18)Most of the time I take almost all statements and actions of others seriously & Female & 159 & 2.97 & 1.211 & \\
\hline or "as is" & Male & 126 & 2.91 & 1.213 & 0.43 \\
\hline & Female & 159 & 4.14 & 0.906 & \\
\hline 19)Being on time and using time effectively are always very important & Male & 126 & 3.79 & 1.076 & 2.99 \\
\hline & Female & 159 & 2.87 & 1.175 & \\
\hline 20)It is seldom necessary to disclose all of one's options & Male & 126 & 3.25 & 1.102 & -2.83 \\
\hline & Female & 159 & 3.21 & 1.397 & \\
\hline 21)I worry often about many things & Male & 126 & 2.53 & 1.484 & $3.95 * * *$ \\
\hline 22)"Do things my way" could well be my motto, because that always feels & Female & 159 & 2.56 & 1.39 & \\
\hline better & Male & 126 & 2.52 & 1.413 & 0.26 \\
\hline 23) Vervoften mu mind ic full fo thourhts that come un agin on & Female & 159 & 3.42 & 1.149 & \\
\hline 23) Very often my mind is full of thoughts that come up again and & Male & 126 & 3.17 & 1.339 & 1.67 \\
\hline 24) At least one of my parents (the person who raised me) may be described as & Female & 159 & 3.22 & 1.516 & \\
\hline "a worrier" & Male & 126 & 3.13 & 1.561 & 0.47 \\
\hline 25) At least one of my parents (the person who raised me) had emotional & Female & 159 & 2.67 & 1.82 & \\
\hline problems when I was growing up & Male & 126 & 2.32 & 1.742 & 1.64 \\
\hline 26) I have suffered from the effects of trauma or a difficult emotional life for & Female & 159 & 2.86 & 1.807 & \\
\hline at least two years & Male & 126 & 2.15 & 1.876 & 3.21 \\
\hline 27) I and/or one parent experienced a dangerous or very threatening personal, & Female & 159 & 1.57 & 1.819 & \\
\hline political and/or military event/s for an extended period & Male & 126 & 1.78 & 1.833 & -0.97 \\
\hline heen/am hein & Female & 159 & 2.18 & 1.675 & \\
\hline ed & Male & 126 & 2.02 & 1.647 & 0.77 \\
\hline & Female & 159 & 3.25 & 1.806 & \\
\hline 29) I and/or one parent has suffered a serious illness & Male & 126 & 3.19 & 1.724 & 0.26 \\
\hline
\end{tabular}




\subsection{Age Group Differences in Overall SOPS/PCPIQ Scores}

One-way ANOVA revealed that there was a significant difference between young (18-39), middle (40-59), and older (60 and higher) age groups on the average SOPS/PCPIQ scores: $\mathrm{F}(2,283)=15.03, \mathrm{p}<.001$. A Tukey post hoc test further revealed that the average SOPS/PCPIQ scores of the older age group $(\mathrm{M}=2.54)$ was statistically significantly lower than that of the middle $(M=2.78)$ and younger age group $(M=3.00)$. The younger age group had a significantly higher average SOPS/PCPIQ score than that of the middle age group $(\mathrm{p}<0.001)$. These results indicated that as the age level increased, the frequency of expressing SOPS/PCP attributes decreased.

\subsection{Age Differences in Individual SOPS/PCPIQ Scores}

Since multiple one-way ANOVAs were conducted, we set alpha as 0.001to avoid inflated type I error (see details in Table 4). As the table shows, 11 out of 29 SOPS/PCP attributes presented age differences. These items were: 3) I look for all the compliments and praise I am due; 4) I often say so when it feels like life is unfair or things are not going my way or in my favor; 5) More than a few times a day I feel frustrated or upset; 9) I often regret things soon after I say or do them; 10) Some of my statements could be (or have been) described as sarcastic humor; 11) I may sometimes react very strongly or "lose it"; 21) I worry often about many things; 22) "Do things my way" could well be my motto, because that always feels better; 23) Very often my mind is full of thoughts that come up again and again; 26) I have suffered from the effects of trauma or a difficult emotional life for at least two years; 29) I and/or one parent has suffered a serious illness.

Tukey post hoc tests were conducted on these items. For all but one of the significant item scores the frequency of expressing SOPS/PCP attributes decreased as the age level increased. The score on only item 29 for the oldest age group $(M=3.71)$ was statistically significantly higher than that for the middle age group $(M=3.34, p<.001)$, which was significantly higher than the score for the youngest age group $(\mathrm{M}=2.73, \mathrm{p}<.001)$. In this case the results indicated that the expression of SOPS/PCP increased with age, as represented by the three age groups.

Table 4. Age group differences in individual SOPS/PCPIQ scores

\begin{tabular}{|c|c|c|c|c|c|}
\hline Item & Group & $\mathbf{N}$ & Mean & $\begin{array}{c}\text { Std. } \\
\text { deviation }\end{array}$ & $\mathbf{F}$ \\
\hline \multirow{3}{*}{$\begin{array}{l}\text { 1) It is normal to be unsure that you are safe from being } \\
\text { harmed or hurt }\end{array}$} & $18-39$ & 104 & 2.91 & 1.39 & \multirow{3}{*}{1.59} \\
\hline & $40-59$ & 99 & 2.69 & 1.40 & \\
\hline & 60 and higher & 83 & 2.58 & 1.13 & \\
\hline \multirow{3}{*}{$\begin{array}{l}\text { 2) It is easy for people to hurt others with unfair criticism } \\
\text { or blame }\end{array}$} & $18-39$ & 104 & 3.41 & 1.30 & \multirow{3}{*}{2.94} \\
\hline & $40-59$ & 99 & 3.74 & 1.00 & \\
\hline & 60 and higher & 83 & 3.36 & 1.16 & \\
\hline \multirow{3}{*}{ 3) I look for all the compliments and praise I am due } & $18-39$ & 104 & 2.77 & 1.35 & \multirow{3}{*}{$16.27 * * *$} \\
\hline & $40-59$ & 99 & 1.97 & 1.24 & \\
\hline & 60 and higher & 83 & 1.8 & 1.21 & \\
\hline \multirow{3}{*}{$\begin{array}{l}\text { 4) I often say so when it feels like life is unfair or things } \\
\text { are not going my way or in my favor }\end{array}$} & $18-39$ & 104 & 2.86 & 1.30 & \multirow{3}{*}{$12.16 * * *$} \\
\hline & $40-59$ & 99 & 2.47 & 1.30 & \\
\hline & 60 and higher & 83 & 1.93 & 1.22 & \\
\hline \multirow{3}{*}{ 5) More than a few times a day I feel frustrated or upset } & $18-39$ & 104 & 2.96 & 1.30 & \multirow{3}{*}{$34.51 * * *$} \\
\hline & $40-59$ & 99 & 2.11 & 1.19 & \\
\hline & 60 and higher & 83 & 1.48 & 1.16 & \\
\hline \multirow{3}{*}{$\begin{array}{l}\text { 6) It is very uncomfortable whenever others find fault with } \\
\text { one's appearance or image }\end{array}$} & $18-39$ & 104 & 3.27 & 1.30 & \multirow{3}{*}{4.48} \\
\hline & $40-59$ & 99 & 2.92 & 1.41 & \\
\hline & 60 and higher & 83 & 2.69 & 1.33 & \\
\hline \multirow{3}{*}{ 7) It is difficult to wait for people or things } & $18-39$ & 104 & 2.96 & 1.33 & \multirow{3}{*}{1.76} \\
\hline & $40-59$ & 99 & 2.73 & 1.30 & \\
\hline & 60 and higher & 83 & 2.61 & 1.28 & \\
\hline \multirow{3}{*}{ 8) I probably speak or act in haste at times } & $18-39$ & 104 & 2.72 & 1.19 & \multirow{3}{*}{.91} \\
\hline & $40-59$ & 99 & 2.57 & 1.19 & \\
\hline & 60 and higher & 83 & 2.49 & 1.18 & \\
\hline \multirow{3}{*}{ 9) I often regret things soon after I say or do them } & $18-39$ & 104 & 2.54 & 1.36 & \multirow{3}{*}{$8.50 * * *$} \\
\hline & $40-59$ & 99 & 1.84 & 1.24 & \\
\hline & 60 and higher & 83 & 2.02 & 1.13 & \\
\hline \multirow{4}{*}{$\begin{array}{l}\text { 10) Some of my statements could be (or have been) } \\
\text { described as sarcastic humor }\end{array}$} & $18-39$ & 104 & 3.59 & 1.18 & \multirow{3}{*}{$11.37 * * *$} \\
\hline & $40-59$ & 99 & 3.22 & 1.35 & \\
\hline & 60 and higher & 83 & 2.69 & 1.33 & \\
\hline & $18-39$ & 104 & 2.59 & 1.42 & \\
\hline
\end{tabular}


11) I may sometimes react very strongly or "lose it"

12) Many situations are difficult in a relationship (whether at work, socially, in the family and/or in romantic situations)

13) The things that make a person very defensive or feel offended are always around you

\begin{tabular}{|c|c|c|c|c|}
\hline $40-59$ & 99 & 2.15 & 1.40 & $9.76 * * *$ \\
\hline 60 and higher & 83 & 1.71 & 1.20 & \\
\hline $18-39$ & 104 & 2.85 & 1.21 & \\
\hline $40-59$ & 99 & 2.68 & 1.23 & 1.22 \\
\hline
\end{tabular}

14) It is always very important to get as much information as there is

15) Order, tidiness and cleanliness are very important

60

$\begin{array}{llll}18-39 & 104 & 2.3 & 1.45\end{array}$

$\begin{array}{lllll}40-59 & 99 & 2.13 & 1.24 & .57\end{array}$

$\begin{array}{llll}60 \text { and higher } & 83 & 2.12 & 1.22\end{array}$

$\begin{array}{llll}18-39 & 104 & 3.99 & 0.89\end{array}$

$\begin{array}{llll}40-59 & 99 & 3.97 & 0.86\end{array}$

$\begin{array}{llll}60 \text { and higher } & 83 & 4.07 & 0.93\end{array}$

$\begin{array}{llll}18-39 & 104 & 3.59 & 0.99\end{array}$

$\begin{array}{lllll}40-59 & 99 & 3.72 & 1.17 & .95\end{array}$

16) I have a definite liking or dislike for certain textures, colors, patterns and/or motion

$\begin{array}{llll}60 \text { and higher } & 83 & 3.8 & 0.99\end{array}$

$\begin{array}{llll}18-39 & 104 & 3.14 & 1.40\end{array}$

$\begin{array}{llll}40-59 & 99 & 3.04 & 1.32\end{array}$

17) It might seem to others that my behavior is opposite to or inconsistent with other behaviors in similar situations

18) Most of the time I take almost all statements and actions of others seriously or "as is"

19) Being on time and using time effectively are always very important

$20)$ It is seldom necessary to disclose all of one's options

21) I worry often about many things

60 and higher $\quad 83 \quad 2.57 \quad 1.53$

$\begin{array}{r}60 \\ \hline 60\end{array}$

\begin{tabular}{llll}
83 & 2.57 & 1.53 \\
\hline
\end{tabular}

$\begin{array}{lcccc}18-39 & 104 & 2.57 & 1.36 & \\ 40-59 & 99 & 2.4 & 1.28 & \end{array}$

$\frac{18}{60}$

$\begin{array}{llll}\text { and higher } & 83 & 1.92 & 1.10\end{array}$

$\begin{array}{llll}18-39 & 104 & 3 & 1.37\end{array}$

$\begin{array}{llll}40-59 & 99 & 3.03 & 1.07\end{array}$

\begin{tabular}{cccc}
\hline 60 and higher & 83 & 2.78 & 1.1 \\
\hline $18-39$ & 104 & 3.88 & 1.07 \\
\hline $40-59$ & 99 & 4.06 & 0.91 \\
\hline
\end{tabular}

1.07

$\begin{array}{cccc}18-30-59 & 99 & 4.06 & 0.91 \\ 60 \text { and higher } & 83 & 4.05 & 1.00\end{array}$

60

$\begin{array}{llll}18-39 & 104 & 2.86 & 1.09\end{array}$

$\begin{array}{llll}40-59 & 99 & 3.15 & 1.22\end{array}$

1.22

\begin{tabular}{|c|c|c|c|c|}
\hline 60 and higher & 83 & 3.14 & 1.14 & \multirow{4}{*}{$10.58 * * *$} \\
\hline $18-39$ & 104 & 3.31 & 1.37 & \\
\hline $40-59$ & 99 & 2.98 & 1.47 & \\
\hline 60 and higher & 83 & 2.35 & 1.45 & \\
\hline $18-39$ & 104 & 2.96 & 1.36 & \multirow{3}{*}{$8.39 * * *$} \\
\hline $40-59$ & 99 & 2.4 & 1.36 & \\
\hline 60 and higher & 83 & 2.18 & 1.37 & \\
\hline
\end{tabular}

that always feels better

23) Very often my mind is full of thoughts that come up again and again

\section{西}

24) At least one of my parents (the person who raised me) may be described as "a worrier"

60

$\begin{array}{lllll}18-59 & -59 & 10.17 * * *\end{array}$

60 and higher $\quad 83 \quad 2.81 \quad 1.29$

$\begin{array}{ccccc}18-39 & 104 & 3.45 & 1.51 & \\ 40-59 & 99 & 3.32 & 1.48 & 6.37\end{array}$

$\begin{array}{lccc}60 \text { and higher } & 83 & 2.7 & 1.54\end{array}$

25) At least one of my parents (the person who raised me) had emotional problems when I was growing up

\begin{tabular}{|c|c|c|c|c|}
\hline $18-39$ & 104 & 2.95 & 1.67 & \multirow{3}{*}{5.44} \\
\hline $40-59$ & 99 & 2.4 & 1.80 & \\
\hline 60 and higher & 83 & 2.12 & 1.84 & \\
\hline $18-39$ & 104 & 2.96 & 1.76 & \multirow{3}{*}{$9.08 * * *$} \\
\hline $40-59$ & 99 & 2.71 & 1.85 & \\
\hline 60 and higher & 83 & 1.86 & 1.86 & \\
\hline $18-39$ & 104 & 1.87 & 1.88 & \multirow{3}{*}{2.61} \\
\hline $40-59$ & 99 & 1.32 & 1.73 & \\
\hline 60 and higher & 83 & 1.8 & 1.83 & \\
\hline $18-39$ & 104 & 2.37 & 1.66 & \multirow{3}{*}{2.88} \\
\hline $40-59$ & 99 & 2.12 & 1.65 & \\
\hline 60 and higher & 83 & 1.78 & 1.63 & \\
\hline $18-39$ & 104 & 2.73 & 1.85 & \multirow{3}{*}{$7.79 * * *$} \\
\hline $40-59$ & 99 & 3.34 & 1.76 & \\
\hline 60 and higher & 83 & 3.71 & 1.52 & \\
\hline
\end{tabular}

27) I and/or one parent experienced a dangerous or very threatening personal, political and/or military event/s for an extended period

28) I have been/am being bullied

29) I and/or one parent has suffered a serious illness 


\subsection{Geographical Differences in Overall SOPS/PCPIQ Scores}

Independent t-test revealed that there was no significant difference between people living in United States and Canada on the average SOPS/PCPIQ score: $\mathrm{t}(284)=0.69, \mathrm{p}=0.50>0.05$.

\subsection{Geographical Differences in Individual SOPS/PCPIQ Scores}

Table 5 presents the related statistics. Column 1 lists the 29 items of SOPS/PCPIQ, which measure the SOPS/PCP attributes. Columns 2 to 5 provide the corresponding group statistics including group, sample size, mean, and standard deviation. The last (column 6) shows the results of independent t-tests. Since multiple t-tests were conducted we set alpha as 0.001 to avoid inflated type I error. As the table shows, no significance was found.

Table 5. Geographical differences in individual scores

\begin{tabular}{|c|c|c|c|c|c|}
\hline Item & Group & $\mathbf{N}$ & Mean & $\begin{array}{c}\text { Std. } \\
\text { deviation }\end{array}$ & $\mathbf{t}$ \\
\hline \multirow{2}{*}{$\begin{array}{l}\text { 1) It is normal to be unsure that you are safe from being } \\
\text { harmed or hurt }\end{array}$} & U.S & 137 & 2.82 & 1.28 & \multirow[b]{2}{*}{1.06} \\
\hline & Canada & 149 & 2.66 & 1.37 & \\
\hline \multirow[b]{2}{*}{$\begin{array}{l}\text { 2) It is easy for people to hurt others with unfair criticism or } \\
\text { blame }\end{array}$} & U. S & 137 & 3.48 & 1.24 & \multirow[b]{2}{*}{-0.39} \\
\hline & Canada & 149 & 3.54 & 1.11 & \\
\hline \multirow[b]{2}{*}{ 3) I look for all the compliments and praise I am due } & U.S & 137 & 2.31 & 1.33 & \multirow[b]{2}{*}{0.73} \\
\hline & Canada & 149 & 2.12 & 1.34 & \\
\hline \multirow[b]{2}{*}{$\begin{array}{l}\text { 4) I often say so when it feels like life is unfair or things are } \\
\text { not going my way or in my favor }\end{array}$} & U.S & 137 & 2.53 & 1.39 & \multirow[b]{2}{*}{0.20} \\
\hline & Canada & 149 & 2.38 & 1.27 & \\
\hline \multirow[b]{2}{*}{ 5) More than a few times a day I feel frustrated or unset } & U.S & 137 & 2.28 & 1.45 & \multirow[b]{2}{*}{0.08} \\
\hline & Canada & 149 & 2.20 & 1.28 & \\
\hline \multirow[b]{2}{*}{$\begin{array}{l}\text { 6) It is very uncomfortable whenever others find fault with } \\
\text { one's appearance or image }\end{array}$} & U.S & 137 & 2.95 & 1.33 & \multirow[b]{2}{*}{.61} \\
\hline & Canada & 149 & 3.01 & 1.39 & \\
\hline \multirow[b]{2}{*}{ 7) It is difficult to wait for people or things } & U.S & 137 & 2.83 & 1.31 & \multirow[b]{2}{*}{.95} \\
\hline & Canada & 149 & 2.73 & 1.31 & \\
\hline \multirow[b]{2}{*}{ 8) I probably speak or act in haste at times } & U.S & 137 & 2.61 & 1.24 & \multirow[b]{2}{*}{0.45} \\
\hline & Canada & 149 & 2.60 & 1.14 & \\
\hline \multirow[b]{2}{*}{$0)$ A } & U.S & 137 & 2.23 & 1.31 & \multirow[b]{2}{*}{0.35} \\
\hline & Canada & 149 & 2.07 & 1.26 & \\
\hline \multirow[b]{2}{*}{$\begin{array}{l}\text { 10) Some of my statements could be (or have been) described } \\
\text { as sarcastic humor }\end{array}$} & U.S & 137 & 3.25 & 1.32 & \multirow[b]{2}{*}{.60} \\
\hline & Canada & 149 & 3.15 & 1.34 & \\
\hline \multirow[b]{2}{*}{ 11) I may sometimes react very strongly or "lose it" } & U.S & 137 & 2.13 & 1.41 & \multirow[b]{2}{*}{-0.59} \\
\hline & Canada & 149 & 2.23 & 1.37 & \\
\hline \multirow[b]{2}{*}{$\begin{array}{l}\text { 12) Many situations are difficult in a relationship (whether at } \\
\text { work, socially, in the family and/or in romantic situations) }\end{array}$} & U.S & 137 & 2.69 & 1.27 & \multirow[b]{2}{*}{-0.19} \\
\hline & Canada & 149 & 2.72 & 1.22 & \\
\hline \multirow[b]{2}{*}{$\begin{array}{l}\text { 13) The things that make a person very defensive or feel } \\
\text { offended are always around you }\end{array}$} & U.S & 137 & 2.24 & 1.36 & \multirow[b]{2}{*}{0.64} \\
\hline & Canada & 149 & 2.14 & 1.27 & \\
\hline \multirow[b]{2}{*}{$\begin{array}{l}\text { 14) It is always very important to get as much information as } \\
\text { there is }\end{array}$} & U.S & 137 & 3.96 & 0.94 & \multirow[b]{2}{*}{-0.79} \\
\hline & Canada & 149 & 4.05 & 0.84 & \\
\hline & U.S & 137 & 3.68 & 1.14 & \\
\hline 15) Order, tidiness and cleanliness are very important & Canada & 149 & 3.70 & 0.98 & -.21 \\
\hline & U.S & 137 & 2.94 & 1.40 & \\
\hline $\begin{array}{l}\text { 16) I have a definite liking or dislike for certain textures, } \\
\text { colors, patterns and/or motion }\end{array}$ & Canada & 149 & 2.94 & 1.46 & .01 \\
\hline 17) It might seem to others that my behavior is opposite to or & U.S & 137 & 2.26 & 1.41 & \\
\hline inconsistent with other behaviors in similar situations & Canada & 149 & 2.38 & 1.17 & -.74 \\
\hline & U.S & 137 & 3.04 & 1.19 & \\
\hline $\begin{array}{l}\text { 18) Most of the time I take almost all statements and actions of } \\
\text { others seriously or "as is" }\end{array}$ & Canada & 149 & 2.86 & 1.23 & 1.30 \\
\hline
\end{tabular}




\begin{tabular}{|c|c|c|c|c|c|}
\hline \multirow[b]{2}{*}{$\begin{array}{l}\text { 19) Being on time and using time effectively are always very } \\
\text { important }\end{array}$} & U.S & 137 & 3.95 & 1.11 & \multirow[b]{2}{*}{-.72} \\
\hline & Canada & 149 & 4.03 & 0.89 & \\
\hline \multirow[b]{2}{*}{ 20) It is seldom necessary to disclose all of one's ontions } & U.S & 137 & 3.18 & 1.10 & \multirow[b]{2}{*}{1.88} \\
\hline & Canada & 149 & 2.92 & 1.19 & \\
\hline \multirow[b]{2}{*}{ 21) I worry often about many things } & U.S & 137 & 2.91 & 1.50 & \multirow[t]{2}{*}{-0.04} \\
\hline & Canada & 149 & 2.92 & 1.45 & \\
\hline \multirow{2}{*}{$\begin{array}{l}\text { 22) "Do things my way" could well be my motto, because that } \\
\text { always feels better }\end{array}$} & U.S & 137 & 2.49 & 1.35 & \multirow[b]{2}{*}{-0.61} \\
\hline & Canada & 149 & 2.59 & 1.44 & \\
\hline \multirow{2}{*}{$\begin{array}{l}\text { 23) Very often my mind is full of thoughts that come up again } \\
\text { and again }\end{array}$} & U.S & 137 & 3.36 & 1.22 & \multirow[b]{2}{*}{.75} \\
\hline & Canada & 149 & 3.26 & 1.26 & \\
\hline \multirow{2}{*}{$\begin{array}{l}\text { 24) At least one of my parents (the person who raised me) may } \\
\text { be described as "a worrier" }\end{array}$} & U.S & 137 & 3.14 & 1.54 & \multirow[b]{2}{*}{-0.53} \\
\hline & Canada & 149 & 3.23 & 1.54 & \\
\hline \multirow{2}{*}{$\begin{array}{l}\text { 25) At least one of my parents (the person who raised me) had } \\
\text { emotional problems when I was growing up }\end{array}$} & U.S & 137 & 2.44 & 1.82 & \multirow[t]{2}{*}{-.75} \\
\hline & Canada & 149 & 2.60 & 1.77 & \\
\hline \multirow{2}{*}{$\begin{array}{l}\text { 26) I have suffered from the effects of trauma or a difficult } \\
\text { emotional life for at least two years }\end{array}$} & U.S & 137 & 2.47 & 1.93 & \multirow[b]{2}{*}{-.74} \\
\hline & Canada & 149 & 2.63 & 1.81 & \\
\hline \multirow{2}{*}{$\begin{array}{l}\text { 27) I and/or one parent experienced a dangerous or very } \\
\text { threatening personal, political and/or military event/s for an } \\
\text { extended period }\end{array}$} & U.S & 137 & 1.94 & 1.83 & \multirow[b]{2}{*}{2.56} \\
\hline & Canada & 149 & 1.40 & 1.78 & \\
\hline \multirow{2}{*}{ 28) I have been/am being bullied } & U.S & 137 & 2.11 & 1.69 & \multirow[b]{2}{*}{-0.23} \\
\hline & Canada & 149 & 2.11 & 1.63 & \\
\hline \multirow{2}{*}{ 29) I and/or one parent has suffered a serious illness } & U.S & 137 & 3.40 & 1.65 & \multirow[b]{2}{*}{1.61} \\
\hline & Canada & 149 & 3.07 & 1.86 & \\
\hline
\end{tabular}

In effect, the location of this SOPS/PCP sample did not affect performance on the SOPS/PCPIQ at all. Gender for the most part - overall or at the item level, except for one case (item 21) demonstrated no significant differences in SOPS/PCPIQ performance. With respect to age however, overall, expression of SOPS/PCP attributes decreased inversely with age group. At the item level, in 11 out of 29 cases this inverse relationship was maintained except for one case that showed a significant increase with increasing age level.

\section{Discussion}

The overall objective of this study was to examine how similar SOPS/PCP is to N, which appears closest to its construct. In this regard the patterns of gender and age were compared with the prevalent evidence for $\mathrm{N}$, including observing whether SOPS/PCP demonstrated a "plaster" or "change" character. The study also considered whether geographical location (in this case Canada and USA) affected the manifestation of SOPS/PCP. Based on the findings there were no gender differences except for a significantly higher frequency and amount of worry among women than men in only one item: "I worry often about many things" (Item 21). This tendency is not surprising given, for example, women's physical and social vulnerabilities in many societies including Canada and the USA and, in general, their child-rearing and domestic responsibilities. Typically, apart from this exception both are equally prone to SOPS/PCP. This overall virtual absence of gender differences in SOPS/PCP however, is in contrast to a preponderance of reports, which consistently present women as more prone to $\mathrm{N}$ than men. Here then is a major difference between SOPS/PCP and N, which, as the original study (Bickersteth, et al., 2018) suggested, represents evidence that SOPS/PCP and N are not identical despite their positive association.

The finding that the frequency of showing SOPS/PCP attributes decreases with increasing age is consistent with the "continuous change" viewpoint. The one item against this pattern (29. I and/or one parent has suffered a serious illness) however, may be explained as representing real life experience. Indeed as people grow older chronic illnesses tend to increase. Nonetheless these results overall show people, in general, would tend to be most vulnerable to SOPS/PCP at the younger age level (ages 18-39) of the three generational levels represented in this study.

Finally as would be expected of two contiguous countries with similar history, culture and social values it is no more or less likely to be prone to SOPS/PCP because of being located in the USA or Canada.

\section{Limitations of the Study and Conclusion}

This size of the samples used in this study greatly reduces confidence in applying the findings beyond the confines of this study. Future research is expected to address this deficiency. As such given the relatively recent introduction of SOPS/PCP into personality literature this study of gender, age and geographical location serves as an initial reference 
point for future research.

To conclude, the gender results, which indicate a departure from the preponderance of the research evidence that consistently shows women with higher mean scores than men in N, reveal a major difference between SOPS/PCP and Big $5 \mathrm{~N}$ as shown in this study of a sample from Canada and the USA.

\section{Funding Information}

The authors received no financial support for this research.

\section{Ethics}

The data for this study came from a previous study (Bickersteth et al., 2018) that met all ethical requirements.

\section{Conflict of Interest}

The authors have no conflict of interest issues involving this research.

\section{References}

Banzhaf, A., Ritter, K., Merkl, A., Schulte-Herbrüggen, O., Lammers, C. H., \& Roepke, S. (2012). Gender differences in a clinical sample of patients with borderline personality disorder. Journal of Personality Disorders, 26(3), 368-380. https://doi.org/10.1521/pedi.2012.26.3.368

Bickersteth, P., Zhang, X. X., \& Guo, Q. (2018). Empirical Evidence for a New Class of Personality Disorder: The Safety-Oriented Personality Style or Phobicentric Psychopathology (SOPS/PCP) and Impact on Personality Psychology. Psychology, 9, 1630-1679. https://doi.org/10.4236/psych.2018.97098

Chapman, B. P., Duberstein, P. R., Sörensen, S., \& Lyness, J. M. (2007). Gender differences in Five Factor Model personality traits in an elderly cohort. Personality and individual differences, 43(6), 1594-1603. https://doi.org/10.1016/j.paid.2007.04.028

Costa, P. T., \& McCrae, R. R. (1988). Personality in adulthood: a six-year longitudinal study of self-reports and spouse ratings on the NEO Personality Inventory. Journal of Personality and Social Psychology, 54(5), 853-863. https://doi.org/10.1037//0022-3514.54.5.853

Kajonius, P., \& Mac Giolla, E. (2017). Personality traits across countries: Support for similarities rather than differences. PloS one, 12(6), e0179646. https://doi.org/10.1371/journal.pone.0179646

Lehmann, R., Denissen, J. J., Allemand, M., \& Penke, L. (2013). Age and gender differences in motivational manifestations of the Big Five from age 16 to 60. Developmental psychology, 49(2), 365-383. https://doi.org/10.1037/a0028277

Lucas, R. E., \& Donnellan, M. B. (2009). Age differences in personality: Evidence from a nationally representative Australian sample. Developmental Psychology, 45(5), 1353-1363. https://doi.org/10.1037/a0013914

McCrae, R. R., Costa Jr, P. T., Hřebíčková, M., Urbánek, T., Martin, T. A., Oryol, V. E., ... Senin, I. G. (2004). Age differences in personality traits across cultures: self report and observer perspectives. European journal of personality, 18(2), 143-157. https://doi.org/10.1002/per.510

McCrae, R. R., Costa, P. T., de Lima, M. P., Simões, A., Ostendorf, F., Angleitner, A., ... Chae, J. H. (1999). Age differences in personality across the adult life span: parallels in five cultures. Developmental psychology, 35(2), 466-477. https://doi.org/10.1037/0012-1649.35.2.466

Rantanen, J., Metsäpelto, R. L., Feldt, T., Pulkkinen, L. E. A., \& Kokko, K. (2007). Long term stability in the Big Five personality traits in adulthood. Scandinavian Journal of Psychology, 48(6), 511-518. https://doi.org/10.1111/j.1467-9450.2007.00609.x

Roberts, B. W., \& Mroczek, D. (2008). Personality trait change in adulthood. Current directions in psychological science, 17(1), 31-35. https://doi.org/10.1111/j.1467-8721.2008.00543.x

Roberts, B. W., Walton, K. E., \& Viechtbauer, W. (2006). Patterns of mean-level change in personality traits across the life course: a meta-analysis of longitudinal studies. Psychological bulletin, 132(1), 1-25. https://doi.org/10.1037/0033-2909.132.1.1

Schmitt, D. P., Realo, A., Voracek, M., \& Allik, J. (2008). Why can't a man be more like a woman? Sex differences in Big Five personality traits across 55 cultures. Journal of personality and social psychology, 94(1), 168-182. https://doi.org/10.1037/0022-3514.94.1.168

Srivastava, S., John, O. P., Gosling, S. D., \& Potter, J. (2003). Development of personality in early and middle adulthood: Set like plaster or persistent change? Journal of personality and social psychology, 84(5), 1041.-1053. 
https://doi.org/10.1037/0022-3514.84.5.1041

Weisberg, Y. J., DeYoung, C. G., \& Hirsh, J. B. (2011). Gender differences in personality across the ten aspects of the Big Five. Frontiers in psychology, 2, 178-189. https://doi.org/10.3389/fpsyg.2011.00178

Wortman, J., Lucas, R. E., \& Donnellan, M. B. (2012). Stability and change in the Big Five personality domains: Evidence from a longitudinal study of Australians. Psychology and aging, 27(4), 867-874. http://dx.doi.org/10.1037/a0029322

Xi, C., Zhong, M., Lei, X., Liu, Y., Ling, Y., Zhu, X., ... Yi, J. (2018). Psychometric Properties of the Chinese Version of the Neuroticism Subscale of the NEO-PI. Frontiers in psychology, 9, 1454-1464.

https://doi.org/10.3389/fpsyg.2018.01454

\section{Copyrights}

Copyright for this article is retained by the author(s), with first publication rights granted to the journal.

This is an open-access article distributed under the terms and conditions of the Creative Commons Attribution license which permits unrestricted use, distribution, and reproduction in any medium, provided the original work is properly cited. 